\title{
Pendekatan Komunikasi Partisipatif sebagai Model Pelaksanaan Program Corporate Social Responsibility (CSR ) JAPFA4Kids
}

\author{
Susilowati Natakoesoemah \\ STIKOM LSPR Jakarta \\ Email : susilowati.n@LSPR.edu
}

\begin{abstract}
Corporate Social Responsibility (CSR) have become an integral of business today. The CSR paradigm have changed, companies should implement CSR with Sustainable Development Goals (SDG'S) approach to its business vision. The principle embodied in Sustainaible Development is essentially the company not only paying attention to corporate profits by maintaining reputation, corporate image or increasing market share but also having to develop the development process without compromising the fulfillment of the needs of future generations. Therefore, SDG's involves 3 pillars or is called "Triple Bottom Line" which is the first to minimize the environmental damage; Second, provide benefits to the communities where the organization is located; Third, provide "economic value" for the company. To implement the principle of CSR program with the principle of $S D G$ 's requires participation from companies and communities, thus to help overcome this solution is required a participatory communication approach in the implementation of CSR. This paper indicates that to encourage changes in daily habits or increase public awareness is not enough only through the development of participatory communication, but also a continuous program with mentoring and knowledge sharing to strengthen attitudes and behaviors on health and nutrition and hygiene.
\end{abstract}

Kata kunci : Corporate Social Responsibility, Sustainable Development Goals, Participatory Communication.

\begin{abstract}
Abstrak
Corporate Social Responsibility (CSR) telah menjadi bagian yang integral dalam industri bisnis saat ini. Paradigma CSR pun telah berubah, perusahaan harus berusaha mengimplementasikan CSR dengan pendekatan Sustainable Development Goals (SDG's) " pada visi businessnya. Prinsip yang dikandung dalam Sustainaible Development pada intinya adalah perusahaan tidak hanya memperhatikan keuntungan perusahaan semata dengan cara menjaga reputasi, corporate image atau meningkatkan market share namun juga harus mengembangkan proses pembangunan tanpa mengorbankan pemenuhan kebutuhan generasi yang akan datang. Oleh karena itu SDG's melibatkan 3 pilar atau yang dikenal dengan "Triple Bottom Line " yakni pertama meminimalisir kerushakan lingkungan; Kedua , memberikan manfaat kepada masyarakat dimana organisasi berada; Ketiga, memberikan "economic value" bagi perushaan. Untuk menjalankan prinsip program CSR dengan prinsip SDG's ini memerlukan partisipasi dari perusahaan maupun masyarakat, maka untuk membantu mengatasi solusi ini diperlukan pendekatan komunikasi partisipatif dalam pelaksanaan program CSR. Makalah ini mengindikasikan bahwa untuk mendorong perubahan perilaku kebiasaan masyarakat sehari-hari atau meningkatkan kesadaran masyarakat tidak cukup hanya melalui
\end{abstract}


pengembangan komunikasi partisipatif, namun diperlukan pula program yang berkesinambungan dengan melakukan mentoring dan berbagi pengetahuan untuk memperkuat sikap dan perilaku terhadap kesehatan dan gizi serta kebersihan.

Kata kunci : Corporate Social Responsibility, Sustainable development Goals, komunikasi partisipatif.

\section{Pendahuluan}

Tanggung jawab sosial perusahaan atau lebih dikenal dengan corporate social responsibility (CSR) saat ini telah menjadi landasan bagi perusahaan dalam menjalankan aktifitas bisnisnya. Cukup banyak perusahaan dalam skala global maupun lokal telah menjalankan bisnisnya dengan mengkaitkan aktifitas CSR sebagai bagian dari strategi bisnis mereka dengan harapan dapat meningkatkan reputasi dan image yang positif, meningkatkan motivasi karyawan serta market share bagi perusahaan (Weber, M, 2009)

Namun sesungguhnya apabila melihat perkembangan CSR saat ini, dalam mengimplementasikan CSR tidak cukup hanya melihat hasil yang diharapkan adalah dari sisi keuntungan perusahaan semata tapi harus pula dilihat bagaimana keberlangsungan dari kualitas hidup komunitas dan sumber daya yang ada. Seperti yang tertera dalam konsep yang dibuat oleh The World Business Councel Development mendefenisikan CSR sebagai komitmen dunia usaha dengan memberikan kontribusinya terhadap keberlangsungan ekonomi serta memperbaiki kualitas hidup dari karywan, keluarga dan masyarakat lokal serta masyarakat umum.

Melihat konsep CSR diatas terlihat Paradigma CSR pun telah mengalami perubahan perusahaan pada visi bisnis nya harus berusaha mengimplementasikan CSR dengan pendekatan Sustainable Development Goals (SDG's)".Prinsip yang dikandung dalam Sustainable Development pada intinya adalah perusahaan tidak hanya memperhatikan keuntungan perusahaan semata dengan cara menjaga reputasi, corporate image atau meningkatkan market share namun juga harus mengembangkan proses pembangunan tanpa mengorbankan pemenuhan kebutuhan generasi yang akan datang (Mickel B Hoelman, et all, 2015) Oleh karena itu SDG's melibatkan 3 pilar atau yang dikenal dengan "Triple Bottom Line " yakni pertama meminimalisir kerusakan lingkungan; Kedua , memberikan manfaat kepada masyarakat dimana organisasi berada; Ketiga, memberikan "economic value" bagi perusahaan (Ihlen, Oyvind, et.al, 2011)

Prinsip yang dituangkan dalam $S D G$ 's tersebut sesungguhnya bukanlah merupakan sesuatu yang tidak beralasan, prinsip tersebut dilandasi bahwa semakin banyaknya perusahaanperushaan yang melakukan kegiatan usahanya telah menimbulkan dampak yang negatif hal ini terlihat dari kritik-kritik yang diberikan oleh para ahli ekonomi bahwa strategi yang mereka lakukan telah menciptakan dan mendorong gaya hidup yang konsumtif yang tinggi dan pola konsumsi yang tidak berkelanjutan (unsustainable) sehingga mendorong diantaranya kerusakan lingkungan yang parah dan polusi. Seperti yang diungkapkan oleh Pingeot dan Scheyvens (2014) bahwa

" ....ranged from maintaining competition position as the leading motivator followed avoiding by reputational damage, avoiding future supply disruptions and capturing revenues and building loyalty (Chakravorti, et al, Dalam Geo Times, 2016). Sehingga apabila hal tersebut tetap berlangsung maka tidak akan terdapat masa depan yang berkesinambungan (sustainable ) karena konsumsi yang terus menerus dan terjadinya degradasi lingkungan. (De Graaf, et al, Dalam Ross Gordon, et.al., 2011)

Sementara itu CSR dalam konteks Indonesia sejak dua dekade terakhir ketertarikan terhadap CSR telah mengalami peningkatan baik bagi perushaan nasional maupun multinasioanl. 
Terutama dengan telah diaturnya $C S R$ dalam undang-undang no 40 tahun 2007 tentang perseroan terbatas pasal 74 yang menjelaskan bahwa setiap perusahaan perseroan yang menjalankan kegiatan usahanya di Indonesia atau yang berkaitan dengan sumber daya alam wajib melaksanakan tanggung jawab sosial dan lingkungannya, jika perusahaan tidak melaksanakan ini maka akan dikenakan sangsi dengan ketentuan peraturan perundangundangan yang telah diatur pemerintah. Disamping itu telah terdapat sejumlah organisasi NGO yang berkontribusi untuk mengembangkan CSR atau sustainability di Indonesia diantaranya KEHATI ( Yayasan keaneka ragaman hayati Indonesia) yang berkolaborasi dengan Bursa Efek Indonesia, dengan memperkenalkan SRI Index KEHATI pada tahun 2009. SRI-KEHATI Ini merupakan indeks yang menjadi indikator gerakan saham di bursa efeik Indonesia (BEI) dengan memperhatikan prinsip keberlanjutan, keuangan, tata kelola yang baik serta keperdulian kepada lingkungan hidup sebagai tolak ukurnya (KEHATI,co.id, 2017).

Dengan adanya undang-undang no 40 tersebut nampaknya telah menempatkan Indonesia pada posisi tertinggi dalam CSR seperti yang diungkapkan oleh Read Brown et.al (2010) bahwa posisi indonesia tertinggi , rangking ke 3 diantara 10 negara ASIAN (China, Hongkong, India, Indonesia, Malaysia, Phillipines, Singapore, Korea Selatan, Taiwan dan Thailand) dan rangking ke 5 secara keseluruhan. (MN. Almunawar \& Kim Cheng Patric 2014). Koestoer (2007) menyatakan bahwa banyak perusahaan di Indoneisa baik lokal maupun multinasional telah menunjukkan CSR mendukung keberlangsungan business.

Pada Data secara empiris menunjukkan bahwa perusahaan-perusahaan di Indonesia menggunakan CSR sebagai suatu kerangka kerja strategis, mereka meyakini bahwa CSR berguna dan penting sebagai strategi bagi perusahaan agar tercipta masa depan dengan memberikan kembali (giving back) kepada masyarakat atau komunitas ( Simon, H \& Fredrik, L, 2009).
Beberapa perusahaan besar di Indonesia telahmengkaitkan bisnisnya dengan $S D G$ 's ini, PT Unilever Indonesia misalnya membuat program yang disebut Unilever Sustainable Living Plan yang visinya, dengan tiga (3 ) tujuan besar yang ingin diraihnya sampai dengan tahun 2020 yakni "membantu jutaan masyarakat memperbaiki kesehatan dan kesejahteraan, mengurangi dampak lingkungan dan meningkatkan taraf hidup".( Saleh, Muhammad, 2015). Dengan kata lain PT Unilever Indonesia membuat komitmen untuk mengembangkan sumber daya manusia, mendukung hak-hak azasi manusia serta mengembangkan produk yang berkualitas dan aman bagi lingkungan. Demikian pula dengan PT Sari Husada, juga telah menerapkan prinsip "triple bottom line " ini yakni secara internal dengan meningkatkan kualitas pengetahuan bagi sumber daya manusia PT Sari Husada melalui program-program training, pendidikan, dan seminar maupun inisiatif sosial lainnya.

Demikian pula dengan perusahaan PT Japfa Comfeed sebagai bentuk tanggung jawab sosial telah membuat program yang disebut dengan Japfa4Kids dengan tema "Anak Indonesia Bersih Dan Sehat", merupakan program CSR yang diselaraskan dengan prinsip "triple bottom line” dari SDG's. program ini merupakan program jangka panjang yang dimaksudkan untuk mempengaruhi perubahan perilaku dari kepala sekolah guru dan semua siswa disekolah sasaran yang terletak disekitar lokasi usaha Japfa agar memperhatikan pola makanan yang sehat dan bergizi serta menciptakan lingkungan sekolah yang sehat. Program tersebut dianggap penting karena didasarkan atas kepercayaan bahwa kesehatan dan gizi anak serta lingkungan akan membawa pengaruh terhadap pengembangan sumber daya manusia dan kesejahteraan masyarakat khususnya dilingkungan sekolah, dalam lingkungan sekolah ini terdapat anakanak bangsa.

Persoalan kesehatan dan gizi anak ini menjadi penting untuk mendapatkan perhatian karena berdasarkan data WHO (2016) mengenai kekurangan gizi pada anak menjukkan bahwa 
kekurangan gizi anak di Indonesia berada diatas ambang batas WHO (CNN Indonesia, 2017)

Banyak faktor yang menyebabkan permasalah terhadap kesehatan dan kekurangan gizi ini, salah satu faktornya adalah faktor sosial dan ekonomi seperti pendidikan, pendapatan dan kualitas lingkungan (Frontier: 2013).

Melihat kondisi tersebut maka setiap perusahaan terutama perusahaan berskala besar menghadapi tantangan bagaimana meningkatkan kesehatan dan gizi melalui promosi kesehatan dan pencegahannya tidak hanya untuk karyawan perusahaan tetapi populasi secaralebih luas. Maka untuk mengatasinya perusahaan sudah harus mulai berperan dalam meningkatkan kesehatan dan pencegahannya dengan upaya menangani tidak hanya untuk karyawan namun juga bagi komunitas lokal dan masyarakat umum. salah satu contoh adalah yang dilakukan oleh PT Japfa Comfeed, melakukan upaya promosi kesehatan dan gizi dengan memfokuskan kegiatannya pada siswa-siswa disekolah dasar yakni dengan memberikan pemahaman terhadap kesehatan terutama pengetahuan terhadap makanan yang sehat terhadap orang tua serta dilingkungan sekolah diantaranya guru dan murid itu sendiri.

Berdasarkan pemaparan tersebut diatas nampak bahwa perusahaan memiliki tanggung jawab sosial yang tinggi terhadap stakeholders yang berada dilingkungan perusahaan, namun demikian tentunya keberhasilan dari program CSR yang dijalankan oleh perusahaan tidak akan berhasil apabila masyarakat kurang memiliki kesadaran untuk mempunyai tanggung jawab sosial terhadap lingkungannya. Terutama dalam masalah kesehatan, berdasarkan penelitian yang dilakukan oleh Frontier (2013) menyebutkan bahwa lebih dari $75 \%$ perusahaan setuju bahwa keterlibatan stakeholders dapat menjadi instrument penting agar mendapatkan dampak yang lebih besar pada kesehatan dan kesejahteraan masyarakat.

Sesungguhnya cukup banyak penelitian dan publikasi yang dibuat terkait dengan CSR, namun sebagian besar penelitian lebih banyak memfokuskan pada hasil dari sisi finansial atau profit perusahaan serta pengaruh yang positif terhadap reputasi perusahaan sedangkan penelitian dari sisi bagaimana pengaruh CSR yang difokuskan pada sisi dampak sosial atas program CSR belum banyak dilakukan.

Seperti yang telah disebutkan diatas bahwa gizi dan kesehatan pada anak merupakan permasalahan serius di Indonesia dan permasalahan ini menjadi perhatian dari PT Japfa Comfeed melakukan CSR dengan melakukan edukasi tentang nutrisi yang sehat yang dikhususkan bagi sekolah dan siswanya dengan memberikan pemahaman dan pengetahuan terhadap makanan dan lingkungan yang sehat.

Maka yang menjadi pertanyaan adalah bagaimana dampak sosial dari program CSR yang dilakukan oleh JAPFA artinya apakah CSR yang dilakukan melalui program Japfa4Kids tersebut dapat merubah pola atau kebiasaan makan anak maupun pengelolaan lingkungan sekolah. Jadi dalam penelitian ini akan difokuskan pada bagaimana dampak sosial dari program CSR.

Apabila melihat perkembangan dari konsep CSR, selama beberapa dekade terakhir CSR mengalami perkembangan yang cukup besar, berbagai disiplin ilmu telah mengkaji CSR dari sudut pandang masing-masing disiplin seperti Management (Makower, 1994), Business Ethics (Caroll, 2000), psychology (Koys, 2001), Sosiologi (Lackey, 1987) dan Organisation development (Kraft, 1991).

Salah satu penelitian terkait dengan CSR yakni dilakukan oleh Mohr, Webb dan Harris (2001) yang memfokuskan penelitian CSR dengan reaksi konsumen yang menunjukkan bahwa konsumen sangat berharap perusahaan memiliki tanggung jawab sosial (E. Brooke, 2009) Sedangkan Sen dan Bhattacharya (2001) melakukan penelitian untuk meentukan "bagaimana, saat kapan dan kepada siapa program CSR tertentu dapat berhasil? Studi lain mengenai pentingnya $C S R$ telah dilakukan oleh Johnson and Johnson dengan memperbaiki kualitas hidup komunitas melalui berbagai program baik di Amerika maupun di seluruh dunia (Dalam E. Brooke, 2009) 
Mengenai pentingnya CSR bagi masyarakat diungkapkan oleh Sheth (Dalam E. Brooke, 2009) bahwa kegiatan CSR difokuskan dalam memenuhi kebutuhan berbagai stakeholder organisasi dan masyarakat secara kesekuruhan sebagai salah satu dari stakeholder. Selain itu lingkungan juga merupakan bagian penting dimana masyarakat hidup. Stuart L, Hart (1995) dari hasil penelitiannya mengungkapkan bahwa perusahaan akan memperoleh competitive advantage apabila memperhatikan dampak lingkungan akibat dari praktik bisnisnya (Dalam E. Brooke, 2009)

Kemudian bagaimana hubungan $C S R$ dengan pembangunan yang berkelanjutan (sustainable development )? Konsep pembangunan berkelanjutan (sustainable development) pada awalnya dikemukakan oleh Komisi Brudland pada tahun 1987, yang didefenisikan sebagai pembangunan yang dapat memenuhi kebutuhan saat ini tanpa mengorbankan kemampuan generasi yang akan datang didalam memenuhi kebutuhan mereka sendiri (Dalam Michele, chen, et. Al, 2017). Elkington juga memperkenalkan konsep yang tekenal dengan jargonnya Triple Bottom Line" yang yakni Pertama meminimalisir kerusakan lingkungan (planet),; Kedua, memberikan manfaat kepada msyarakat dimana organisasi berada (people); dan ketiga memberikan econnomic value (profit) (Hoqwood, Bill, et.el, 2006). Sementara Dyllick dan Hockerts (Dalam Michele, et.al, 2017) berpendapat bahwa didalam konsep pembangunan yang berkelanjutan terdapat dua dimensi yang harus dipahami yakni kelangsungan hidup jangka pendek dan pembangunan berkelanjutan jangka panjang. Dalam perpespektif ini, lebih jauh , Bansal (2002) berpendapat bahwa keberlanjutan adalah suatu konsep dimana perusahaan tidak hanya mementingkan kesejahtaeraan perusahaannya dalam jangka pendek namun juga untuk pembangunan seluruh masyarakat dalam jangka panjang, dengan kata lain perusahaan sebaiknya dapat memenuhi kebutuhan pemangku kepentingan langsung atau tidak langsung dari perusahaan seperti pemegang saham , karyawan, klien , komunitas dsbnya, tanpa mengorbankan kemampuan generasi yang akan datang (Dalam Michele, chen, 2017).

Hubungan antara sustanaible

development dengan CSR juga dikaji oleh Ebner dan Baumgarter (2006) dengan melihat apakah CSR merupakan bagian dari Sustainable Development atau CSR sama dengan Sustanaible Development . Hasilnya menujukkan bahwa terdapat hubungan yang kuat antara CSR dengan Sustanaible Development, kemudian peneliti lain mengindikasikan bahwa CSR adalah dimensi sosial dari Sustanaible Development.

Lebih jauh Moscardo Lamberton Wels, et.al (2013) mengatakan bahwa CSR merupakan komitment bisnis untuk berkontribusi pada pembangunan ekonomi yang berkelanjutan, bekerja dengan karyawan, keluarga mereka, komunitas lokal dan masyarakat pada umumnya untuk memperbaiki kualitas hidup mereka (Dalam Issa, T \& Theodore, 2017) Hal ini menunjukkan bahwa bisnis harus memasukkan dan mengintegrasikan CSR kedalam strategi mereka untuk membantu komunitas dan masyarakat baik secara lokal maupun global.

Kotler \& Nancy (2005) berpendapat bahwa terdapat enam (6) aktifitas sosial sebagai wujuddariCSR yakni; Pertama, Cause Promotion, pada aktifitas ini perusahaan menyediakan atau memberi sumber daya yang ada melalui penggalangan dana atau volunter untuk isu sosial tertentu yang bertujuan untuk meningkatkan kesadaran masyarakat; Kedua, Corporate Social Marketing, perusahaan memberikan dukungan dengan melakukan kampanye mengenai isu sosial tertentu yang bertujuan untuk merubah perilaku masyarakat terhadap kesehatan masyarakat atau isu-isu kesehatan , keselamatan, lingkungan atau kesejahteraan masyarakat; Ketiga, Cause Related Marketing, pada kampanye ini perusahaan berkontribusi terhadap isu sosial tertentu dengan memberikan persentase keuntungan dari hasil penjualan; Keempat, Corporate Philantropy, perushaan memberikan kontribusi secara langsung dengan 
melakukan kegiatan amal biasanya dalam betuk donasi, grant atau jasa lainnya kepada masyarakat yang membutuhkan. Kelima, Community Volunteering, merupakan kegiatan dari perusahaan dengan memberikan dukungan danmendorong karyawan untuk menyediakan waktu dan tenaganya untuk membantu suatu isu sosial tertentu; Keenam, Socially Responsible Business Practices, perusahaan menjalankan praktik biusines yang mendukung tgujuan sosial untuk memperbaiki kesejahteraan sosial komunitas dan mnelindungi lingkungannya.

Berdasarkan uraian diatas terlihat salah satu aktifitas CSR yakni Coporate Social Marketing ada relevansinya dengan program CSR Japfa4Kids. Dalam program ini pada dasarnya adalah ingin mendorong perubahan perilaku dari stakeholders yang berada dilingkungan sekolah mulai dari kepala sekolah, siswa dan orang tua yakni dengan memberikan pemahaman akan pentingnya makanan sehat sekaligus menjaga lingkungan yang sehat.

\section{Metode Penelitian}

Metode yang digunakan dalam penelitian ini dengan menggunakan pendekatan kualitatif dan bersifat penelitian evaluatif yakni mengevaluasi pelaksanaan program CSR Japfa4Kids yang dilakukan pada sekolah Dasar didaerah garut yaitu SD Mekar Galih dan SD Suka Galih Garut. Data primer didapat melalui interview dengan informan yang relevan yaitu Kepala Sekolah, siswa sekolah dasar, guru, orang tua, dan tenaga kesehatan (Puskesmas).

Sementara itu data sekunder diperoleh dari dokumen-dokumen yang ada yakni laporanlaporan tertulis dan panduan pelaksanaan program. Data yang terkumpul dianalisis dengan tehnik deskriptif kualitatif. Pertama-tama keseluruhan data disajikan dalam display data kemudian direduksi mana yang relevan dengan pokok permasalahan. Tahap berikutnya adalah membuat interpretasi dan memberi kesimpulan.

\section{Hasil dan Pembahasan Penelitian}

Program Japfa4Kids merupakan program yang dibuat oleh Japfa comfeed sebagai bentuk pelaksanaan tanggung jawab sosial perusahaan terhadap masyarakat sekitar operasional dengan menerapkan prinsip triple bottom line. Program ini didasarkan atas kepercayaan bahwa kesehatan dan gizi anak, serta lingkungan membawa pengaruh besar terhadap pengembangan sumber daya manusia dan kesejahteraan masyarakat.

Progam Japfa4Kids ini dibagi kedalam 2 aktifitas besar yang disebut dengan Program Sekolah Sehat dan Program Sekolah Nyaman. "Program Sekolah sehat" ini secara umum bertujuan menumbuhkan kesadaran akan makanan sehat, menjaga kesehatan sekaligus memperkenalkan tanaman sehat yang ada dilingkungan sekitar dan manfaatnya kepada siswa sekolah. Program yang dilakukan adalah dengan menunjuk siswa sebagai "Dokter Kecil atau duta anak sehat, Duta makanan sehat atau koki kecil dan pembinaan kantin sehat.

Kemudian program besar yang kedua disebut dengan "Sekolah Nyaman"; program ini merupakan program dengan konsep sekolah yang bersih dan teratur yang dilakukan bersamasama dengan semua komunitas sekolah, guru, staf siswa serta orang tua siswa untuk mendorong anak-anak memiliki sifat disiplin , tekun dan menghargai. Melalui program ini semua komunitas sekolah ikut terlibat dalam kegiatan-kegiatannya. Kegiatan yang dilakukan melalui program ini adalah dengan melakukan yang disebut dengan $5 \mathrm{~S}$ yaitu memperkenalkan dan membiasakan kepada warga sekolah untuk mengelola sarana dan prasana sekolah, selain itu juga melakukan gerakan sekolah bersih dan menunjuk siswa untuk menjadi "Duta Lingkungan Sekolah"

Didalam pelaksanaan semua program tersebut diatas komunikasi memainkan peranan yang sangat mendasar dalam menyampaikan pesan terutama didalam menyampaikan suatu pengetahuan yang sifatnya baru maka diperlukan komunikasi yang sifatnya lebih intens, salah satu model komunikasi yang dapat digunakan dalam proses pemberian pemahaman adalah dengan komunikasi partisipatif. Caldevia berpendapat 
bahwa apabila program yang dilakukan adalah untuk memberikan pemahaman dan pengetahuan adalah dengan melakukan komunikasi yang bersifat partisipatif. ( Dalam, Mefalopulos, 2003)

Komunikasi partisipatif merupakan proses sosial dimana kelompok dengan minat yang sama membangun pesan yang beorientasi terhadap kondisi kehidupan mereka. Pengukuran keberhasilan dalam pelaksanaan program tersebut didasarkan pada pencapaian target luaran yang telah dibuat sebelumnya. Dalam konteks ini apabila dikaitkan dengan target luaran yang diharapkan pada program ini yaitu (1) Siswa mampu menjaga kebersihan , kesehatan, kerapihan dan ketertiban diri dan lingkungan serta mampu mengelola dan memanfaatkan sumber makanan sehat; (2) Guru mampu menjaga kebersihan, kesehaan, kerapihan dan ketertiban diri dan lingsungan serta mampu dalam penerapan Pelaksanaan Hidup Bersih dan Sehat (PHBS) dan 5 S (Pilah, tata, bersihkan, mantapkan dan biasakan ); (3) Kepala Sekolah mampu menjaga kebersihan, kesehatan, kerapihan, ketertiban diri dan lingkungan sekolah, mampu membuat kebijakan terkait PHBS dan 5S serta mendampingi guru dalam penerapan PHBS dan 5S di sekolah. Bersama dengan orang tua, Kepala Sekolah memperhatikan dan mendorong pemenuhan gizi anak. Komunikasi partisipatif untuk mencapai target luaran tersebut dilakukan melalui pembinaan dalam bentuk pelatihanpelatihan dan bekerja sama dengan unsurunsur yang terkait dalam sekolah seperti kepala sekolah, guru, orang tua dan pemilik kantin, untuk menumbuhkan kesadaran akan pentingnya memberi makanan sehat pada anak dan menjaga maupun mengelola lingkungan yang sehat mengengenali jajanan tidak sehat, serta pelatihan tentang bagaimana mengolah makanan dengan sehat (demo masak sehat).

Dalam konteks hasil luaran yang diharapkan "Siswa mampu menjaga kebersihan , kesehatan, kerapihan dan ketertiban diri dan lingkungan serta mampu mengelola dan memanfaatkan sumber makanan sehat ini, diukur dengan bagaimana tingkat pengetahuan dan pemahamannya. Pada hasil penelitian ditemukan bahwa siswa merasakan perubahan perilaku yang cukup baik. Menurut orang tua dari siswa ketika ditanyakan perubahan apa saja terdapat didalam diri siswa setelah menerima pelatihan dan pembinaan terhadap program Japfa4Kids , mereka mengatakan bahwa "perubahan yang saya rasakan sangat banyak, anak saya mau belajar memasak, sebelumnya tidak mempunyai keahlian memasak. Disamping itu anakanak mmemiliki pengetahuan atas pentingnya kesehatan seperti bagaimana cara menggosok gigi yang baik dan sangat antusias menjadi duta anak sehat. Disamping itu siswa menujukkan keperduliaannya terhadap makan sehat. Perubahan ini tidak hanya terjadi pada siswa tetapi juga pada guru, mereka dapat memahami bagaimana membuat makanan yang sehat.

Selanjutanya untuk mencapai hasil luaran agar "Guru mampu menjaga kebersihan, kesehatan, kerapihan dan ketertiban diri dan lingsungan serta mampu dalam penerapan Pelaksanaan Hidup Bersih dan Sehat (PHBS) dan 5 S (Pilah, tata, bersihkan, mantapkan dan biasakan) " yakni dengan cara guru-guru memberikan pendampingan terhadap siswasiswa untuk menjaga kebersihan sekolah dan guru melaksanakan pola hidup sehat serta bersih. Pengukuran hasil luaran dilihat murid dapat menjaga kebersihan kelasnya, membuang sampah pada tempatnya dan guru dapat memberikan contoh perilaku yang baik terhadap murid ini.

Sedangkan untuk pengukuran hasil luaran "Kepala Sekolah mampu menjaga kebersihan, kesehatan, kerapihan, dan ketertiban diri dan lingkungan sekolah, mampu membuat kebijakan terkait PHBS dan 5S serta mendampingi guru dalam penerapan PHBS dan 5S di sekolah". Kepala Sekolah mengawasi penerapan PHBS di lingkungan sekolah oleh warga sekolah, serta Kepala sekolah membahas praktik PHBS, termasuk pemenuhan gizi anak/siswa kepada orang tua dan Kepala sekolah melibatkan orang tua/komite dalam menyusun rencana penerapan 
PHBS dan 5S di sekolah. Disamping itu Kepala sekolah mendorong praktik hidup sehat dan bersih dilakukan orang tua di rumah masingmasing. Hasil yang didapat melalui program ini adalah sekolah dapat memperbaiki kondisi sekolah, sekolah yang selama ini tidak pernah mempunyai kantin yang sehat, tanaman toga, bahkan untuk toilet pun tidak layak.

Jika melihat Pelaksanaan dari kegiatankegitan tersebut diatas menunjukkan adanya partisipasi aktif dan dialog diantara partisipan. Dialog tersebut merupakan salah satu bentuk dari komunikasi partisipatif seperti yang dikemukan oleh Arnst (1996) bahwa melalui partisipasi yang aktif dan dialog, dapat membantu komunitas untuk mengidentifikasi kebutuhan mereka dan memberikan petunjuk terhadap sumber-sumber daya yang tersedia. Masyarakat hanya dapat mencapai potensi yang penuh ketika mereka diberikan kebebasan untuk berfikir dan bertindak melalui cara yang tepat. ( Dalam, Chitnis, S, 2005).

Walaupun nampaknya model komunikasi partisipatif cukup berhasil dalam menciptakan pemahaman dan pengetahuan, namun hasil yang diharapkan tidak cukup maksimal karena ternyata dalam menciptakan perubahan perilaku dalam jangka panjang tidak cukup hanya dengan melakukan pendekatan komunikasi partisipatif, tantangan yang cukup berat didalam melakukan usaha menciptakan perubahan perilaku secara jangka panjang adalah dengan melakukan "mentoring" secara berkesinambungan. Mentoring didefenisikan sebagai hubungan yang profesional dimana orang yang berpengalaman membantu orang lain dalam mengembangkan keahlian dan pengetahuan khusus yang akan membantu pengembangan diri seseorang (Management mentor.com 2018). Disamping itu kendala lain yang dihadapi adalah sangat terkait dengan sumber dana dan kesadaran dari orang tua siswa terhadap pentingnya tanggung jawab secara sosial. Hal ini terungkap dari hasil penelitian bahwa para guru mempertanyakan bagaimana tindak lanjut dari program ini setelah tidak ada lagi bantuan dari Japfa, karena mereka merasa bahwa program pembinaan dan pendidikan ini membutuhkan biaya sedangkan dari pihak sekolah tidak ada dana khusus dalam menyelenggarakan program tersebut, terutama untuk pembuatan kantin sehat atau perbaikan infrastruktur dalam sekolah sangat diperlukan dana yang cukup.

Kendala lainnya adalah kesadaran dari pihak orang tua siswa yang kurang mendukung pelaksanaan dari program ini, orang tua siswa merasa bahwa program-program yang dilakukan diluar jam belajar sekolah sangat menggangu pelajaran dan mereka berpedapat bahwa programprogram tersebut hanya sekedar coba-coba saja. Disamping itu para gurupun mengatakan bahwa kendala dari program ini adalah dari pihak orang tua yang dianggap kurang bisa diajak kerjasama.

Sementara itu program-program yang dilakukan Japfa apabila dilihat dari sisi perusahaan, nampaknya memiliki dampak yang positif terhadap bisnisnya. Seperti yang dikemukakan oleh pihak Japfa sendiri bahwa komplain masyarakat terhadap japfa berkurang karena melihat Perusahaan peduli terhadap lingkungan dan pendidikan. Hal yang sama juga diungkapkan oleh Choirulah (2009) dan Darwin (2009) bahwa CSR digunakan untuk mendapatkan penerimaan dari komunitas lokal , legitimasi, profit dan pertumbuhan yang berkelanjutan (Dalam Simon, H \& Fredrik, L , 2009).

\section{Simpulan}

Berdasarkan hasil penelitian terlihat bahwa pelaksanaan program CSR melalui pendekatan komunikasi partisipatif dengan melibatkan siswa, guru, kepala sekolah dan orang tua menunjukkan indikator yang positif hal ini ditunjukkan dengan antusiasme dari siswa-siswa ketika ditunjuk sebagai duta makanan sehat dan dokter kecil. Disamping itu melalui pendampingan dan pelatihan mampu meningkatkan pemahaman dan pengetahuan sertaketertarikan baik siswa maupun guru terhadap pola makan yang sehat, dan ada keinginan belajar memasak dari anak. Demikian pula dengan pengelolaan dan pemeliharaan 
terhadap prasarana sekolah terutama toilet, siswa dan guru mampu memanfaatkan sarana yang ada diantaranya membuat tanaman obat mini serta memperbaiki kondisi sekolah, sekolah telah memiliki kantin yang sehat, tanaman TOGA dan toilet yang layak.

Namun demikian terdapat tantangan yang dihadapi dalam program tersebut yakni terkait dengan sumber dana dan kesadaran dari orang tua siswa terhadap pentingnya tanggung jawab secara sosial, mereka merasa bahwa program pembinaan dan pendidikan ini membutuhkan biaya sedangkan dari pihak sekolah tidak ada dana khusus dalam menyelenggarakan program tersebut, terutama untuk pembuatan kantin sehat atau perbaikan infrastruktur dalam sekolah sangat diperlukan dana yang cukup.

Disamping itu tantangan lain ternyata hanya dengan pendekatan partisipatif yang dilakukan hanya dalam rentang waktu 2 bulan tidak lah cukup karena sifat dari program ini bertujuan untuk terjadinya perubahan perilaku. Maka untuk terjadinya perubahan perilaku diperlukan pendampingan yang berkesinambungan, maka dalam penelitian ini mencoba menawarkan pendekatan baru yakni melalui pendekatan mentoring yang berkesinambungan yakni pendekatan dengan bantuan dari orang yang berpengalaman untuk mengembangkan keahlian dan pengetahuan khusus bagi partisipan.

\section{Daftar Pustaka}

Almunawar, MN.\& Patric, Kim Cheng, 2014, Corporate Social Responsibility And Sustainable Development. Springer, London. Bhagwat, Prajali, 2011, Corporate Social Responsibility And Sustainable Development. Institute Management of Technology. Cakravorti, et.al, 2016, Geo Times Indonesia. Chitnis, 2005, Communication For Empowerment And Participatory Development, India. CSR Netherlands, 2016. Country Scan CSR In Indonesia.
Ellen, Brooke, 2009. The Social Impact Of Corporate Social Responsibility : A Case Study. Florida State University. Frontier, 2013. A New CSR : Business And Population Health: Mobilizing CSR to Strengthen Corporate Engagement On health And Welness Across The Value Chain, 2013. BSR). Ihlen, Oyvind, et.al, 2011. The Handbook Of Communication And Coporate Social Responsibility. Issa, $T \&$ Theodore, 2017, $4^{\text {th }}$, International Conference On CSR Sustainaibility, Ethics \& Government. Perth, Australia. KEHATI,co.id, 2017.

Management Mentor, 2018, Management Mentor . com

Kotler, P \& Lee, Nancy , 2005. Corporate Social Responsibility:Doing The Most GoodFor Your Company And Your Cause. Wiley Mefapolus, Paolo, 2003. Theory And Practice Of Participatory Communication. The University Of Texas.

Mickel, B. Hoelman, et.al, 2015. MDG and SDG'S: Global Goals For 15 Years. Michele Chen, 2017. Angka Kekurangan Gizi Diambang Batas WHO; World Commision On Environment And Development, CNN Indonesia, 2017. Mohr, Lois , et.al. Do Consumers Expect Companies TO Be Socially Responsibility On Buying Behaviour. JAPFA, Panduan Pelaksanaan Program, 2017. Ross, Gordon, et.al. 2009. A frame work For Sustainable Marketing.

Saleh, Muhammad, Unilever Corporate Social Responsibility, 2015.

Simon, Hendeberg \& Fredrik, Lndgren, 2009. CSR In Indonesia : A Qualitative Study From A Managerial Prespective Regarding Views And Other Important Aspects Of CSR In Indonesia Stead,Martine, et.al,2007.ASystematicReviewOf Social Marketing Effectiveness. Emerald Group Publishing Limited. Stirling. 